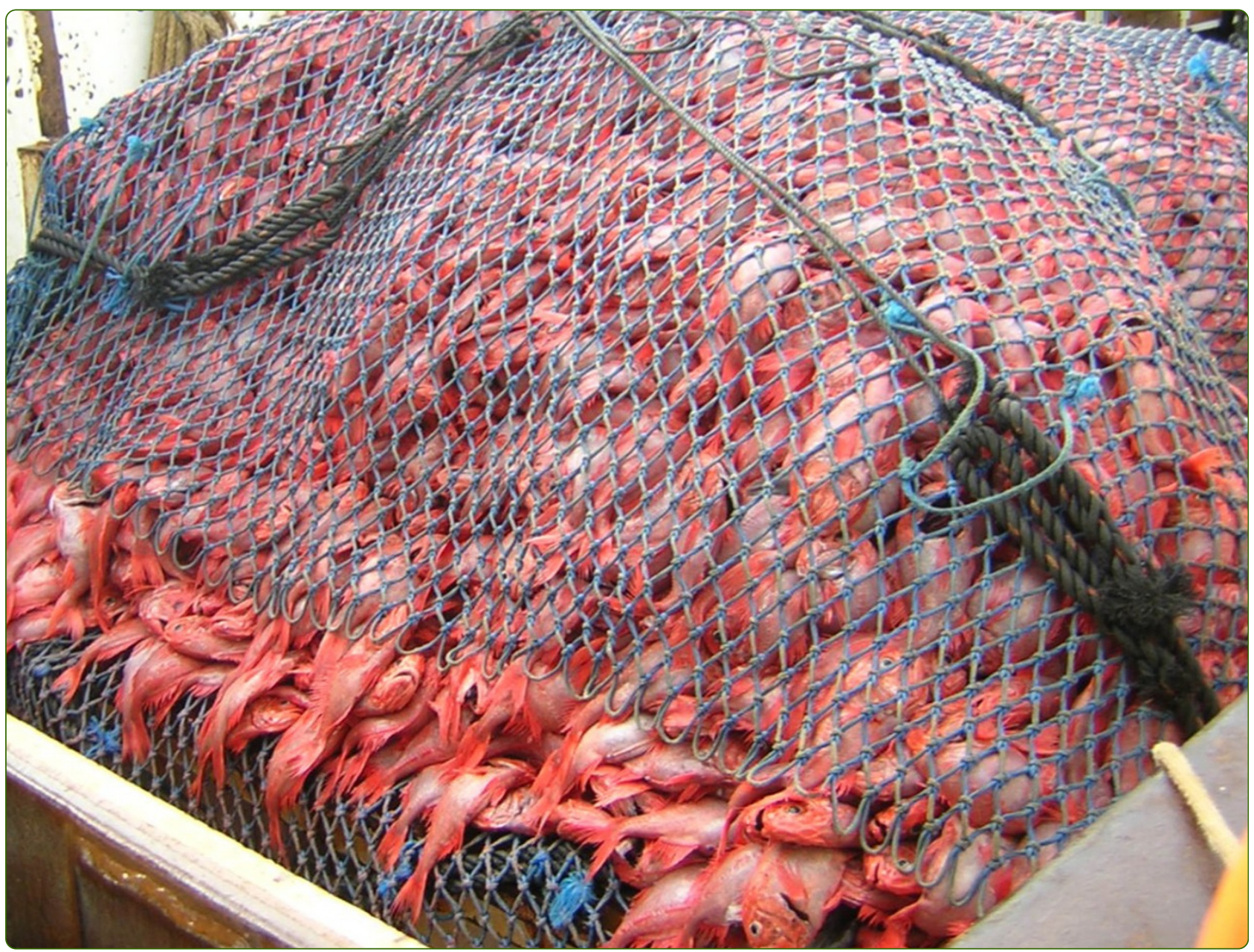

\title{
Investigating the effects of mobile bottom fishing on benthic biota: a systematic review protocol
}

Hughes et al. 


\title{
Investigating the effects of mobile bottom fishing on benthic biota: a systematic review protocol
}

\author{
Kathryn M Hughes ${ }^{1 *}$, Michel J Kaiser ${ }^{1}$, Simon Jennings ${ }^{2}$, Robert A McConnaughey ${ }^{3}$, Roland Pitcher ${ }^{4}$, Ray Hilborn ${ }^{5}$, \\ Ricardo O Amoroso ${ }^{5}$, Jeremy Collie ${ }^{6}$, Jan Geert Hiddink', Ana M Parma ${ }^{7}$ and Adriaan Rijnsdorp ${ }^{8}$
}

\begin{abstract}
Background: Mobile bottom fishing, such as trawling and dredging, is the most widespread direct human impact on marine benthic systems. Knowledge of the impacts of different gear types on different habitats, the species most sensitive to impacts and the potential for habitats to recover are often needed to inform implementation of an ecosystem approach to fisheries and strategies for biodiversity conservation. This knowledge helps to identify management options that maximise fisheries yield whilst minimising negative impacts on benthic systems.

Methods/design: The methods are designed to identify and collate evidence from experimental studies (e.g. before/after, control/impact) and comparative studies (spanning a gradient of fishing intensity) to identify changes in state (numbers, biomass, diversity etc.) of benthic biota (flora and fauna), resulting from a variety of mobile bottom fishing scenarios. The primary research question that the outputs will be used to address is: "to what extent does a given intensity of bottom fishing affect the abundance and/or diversity of benthic biota?" Due to the variety of gear and habitat types studied, the primary question will be closely linked with secondary questions. These include: "how does the effect of bottom fishing on various benthic biota metrics (species, faunal type, trait, taxon etc.) vary with (1) gear type and (2) habitat, and (3) gear type-habitat interactions?" and (4) "how might properties of the community and environment affect the resilience (and recovery potential) of a community to bottom fishing?"
\end{abstract}

Keywords: Mobile bottom fishing, Trawling, Dredging, Benthos, Impact, Recovery

\section{Background}

For the purposes of this protocol, "bottom fishing" will be the term used to describe any fishing method that physically disturbs the seafloor. Bottom fishing will include trawling, dredging, raking and suction fishing methods, but does not include static passive methods such as lobster or crab pots, fyke nets or static nets.

The ecosystem approach to fisheries requires that managers take account of the ecosystem effects of fishing and manage to ensure these effects are sustainable $[1,2]$. Bottom fishing causes high levels of abrasive physical disturbance and is one of the most extensive human activities impacting the seafloor and associated biota [3]. Consequently, managers need an evidence base to assess the effects of bottom fishing and to underpin advice on

\footnotetext{
*Correspondence: kathrynhughes1983@gmail.com

${ }^{1}$ School of Ocean Sciences, Menai Bridge, Bangor University, Wales LL59 5AB, UK

Full list of author information is available at the end of the article
}

the sustainability of alternate fishing methods and management options [1,2].

The relative impact of towed bottom fishing gear on the benthic system has been a long-running and widespread topic of debate within the scientific and broader community. A number of published papers explore local or regional impacts of trawling on benthic biota [4-6], as well as several previous reviews of the impacts of bottom fishing [3,7-13]. Other research consortia have also focused on the issue of bottom fishing impacts over the last 25 years. For example, the International Council for the Exploration of the Sea (ICES) has reviewed the impacts of trawling in the Working Group on Ecosystem Effects of Fishing Activities (WGECO); alongside the Working Group on Fishing Technology and Fish Behaviour (WGFTFB) which led to proposals for ways to reduce seabed impact through changes in gear design and methods of deployment [14-18]. 
The aim of this systematic review is to assemble a comprehensive database on the impacts of bottom fishing on benthic biota from published literature. The objectives of the review are: to capture literature published since a previous review [3] using a robust, reliable and repeatable method (i.e. a systematic review), to collate an up-to-date open access database on mobile bottom fishing impact studies on shelf seas that also includes non-experimental studies on fishing impacts at the scale of the fishery (comparative studies - see below).

There are two main classes of bottom fishing impact study described in the scientific literature: experimental and comparative [19].

Experimental studies measure abiotic/biotic characteristics of the study site before and/or after one or a series of controlled bottom fishing events, sometimes alongside a control site [19]. Data collected during experimental studies are useful to determine the direct impact of a known level of disturbance $[10,20]$. However, a primary drawback of experimental studies is that the experimental study area is generally not representative of the spatio-temporal scale of the fishery [21-24]. Habitats and communities that are exposed to bottom fishing disruption over a larger spatial scale and longer time frame, such as those in commercial bottom fishing grounds, may have recovery trajectories that differ from those habitats and communities exposed to a one-off disturbance event over a smaller area, such as occurs after experimental trawling [21,24,25]. Further, few studies assess the effects of repeated commercial fishing impacts over several months or a year [26-28]. Comparative studies use data collected from sites subject to different intensities of bottom fishing disturbance and, in some cases unfished control sites, to assess the effects of trawling [19]. Here, the state of the seabed community indicates the impact of real bottom fishing events. It can be difficult to quantify reliably the intensity of bottom fishing effort at a given sampling site because the impact of fishing effort can rarely be measured at the fine resolution of sampling. Consequently, a mis-match in scales between sample collection and the area assigned a given fishing intensity may reflect local heterogeneity of fishing effort which may bias results [29].

Existing research suggests that the impact of bottom fishing depends on:

- The gear-type used (design, rigging, deployment, see [30])

- The habitat being fished

- The intensity of fishing in any given area [12]

- The species or community at the fishing site [3]

- The level of natural disturbance that occurs at the site

Results of experiments may describe a general impact scenario, where a given gear reduces the abundance of benthic biota [3,13], or more complex scenarios that account for variation in natural disturbance levels, differing gear types and changes in the intensity of impact [13]. Interactions between trawling intensity, habitat type, natural disturbance levels [13], gear type and the biological species present at the sampling site, may result in small scale local, site and gear specific relationships with impact that are not necessarily stable in time and space. For example, a previous meta-analysis of multiple studies showed that deposit and suspension feeders were most at risk from scallop dredging, whilst their susceptibility to other gear types depended on habitat type [3].

\section{Aim and objectives of the review}

The aim of this systematic review is to assemble a comprehensive up-to-date database on the impacts of bottom fishing on benthic biota on shelf seas, from published literature. The information collated in this database will subsequently be used to answer primary and secondary questions.

\section{Primary question}

To what extent does bottom fishing affect the numerical abundance, biomass and diversity of benthic biota?

To further clarify the components of the primary question and to specify factors relevant to the inclusion/ exclusion criteria, the primary question was sub-divided (Table 1).

\section{Secondary questions}

a) How does the effect of bottom fishing on benthic biota vary with gear type?

b) How does the effect of bottom fishing on benthic biota vary with habitat type?

c) To what extent is there an interaction between gear type and habitat type with respect to the effect of bottom fishing on benthic biota?

d) How might species diversity affect the resilience (including recovery potential) of a community to bottom fishing effects?

To assess whether our questions were relevant to fisheries stakeholders as well as scientists and fishery managers, we consulted with a group of stakeholders to identify their relevance in relation to their priority questions about fishing impacts (see [32] for more details on the stakeholder consultation process, alongside (Additional file 1)).

\section{Methods}

\section{Search strategy}

Searches will be carried out to ensure we access data in both grey literature and peer-review journals to minimise the possibility of publication, and related, biases. The 
Table 1 Definition of components of the primary systematic review question as per the CEE guidelines [31]

\begin{tabular}{|c|c|c|c|c|}
\hline $\begin{array}{l}\text { Subject } \\
\text { Population }\end{array}$ & Exposure & Biological outcome measures & Comparators & Designs \\
\hline $\begin{array}{l}\text { Marine } \\
\text { benthic } \\
\text { biota }\end{array}$ & $\begin{array}{l}\text { Short or } \\
\text { long-term } \\
\text { use of } \\
\text { bottom } \\
\text { fishing gear }\end{array}$ & $\begin{array}{l}\text { Changes in abundance measures } \\
\text { (density/biomass, etc.), and diversity } \\
\text { measures (e.g. species richness) } \\
\text { of benthic biota. Changes in abiotic } \\
\text { components and other biological } \\
\text { variables will also be recorded where } \\
\text { available }\end{array}$ & $\begin{array}{l}\text { Areas with no bottom fishing } \\
\text { (e.g. marine protected areas), or } \\
\text { low levels of bottom fishing } \\
\text { (e.g. sites with effort restrictions) }\end{array}$ & $\begin{array}{l}\text { Any primary study that provides raw data } \\
\text { measures of numerical abundance, biomass or } \\
\text { diversity of benthic biota. The methods of the } \\
\text { primary study should be either a 'before and } \\
\text { after' or 'control and impact' study (or both i.e. } \\
\text { BACI), or based on comparisons of at least two } \\
\text { different levels of bottom fishing exposure or } \\
\text { comparisons between areas exposed to bottom } \\
\text { fishing and control areas. }\end{array}$ \\
\hline
\end{tabular}

bibliography of any articles selected for the final review will also be searched, for any literature missed in the initial searching processes. If missing articles are identified these will be screened with the same inclusion/exclusion criteria applied to the original sources and may be added to the final review bibliography if found relevant. At the searching and screening stage, the experimental and comparative studies will be treated the same way, but identified for easy separation in subsequent analyses. Experimental and comparative studies usually differ in their methodology and aims and it is likely they will need to be treated differently at the analysis stage. Since the searching process will be limited by time and financial resources this will be taken into account when scoping the search and to achieve a balance between sensitivity and specificity of the search. Scoping the search is a term used to describe the process of determining the most appropriate search term, optimising specificity and sensitivity. Specificity is the ability of a search to identify only relevant articles whilst sensitivity is the ability of a search term to find all relevant articles. (Additional file 2) provides more details on scoping the search.

\section{Search terms}

Some websites will allow complex search queries to be written as one search string that are joined by Boolean operators such as "AND/OR/NOT", as well as using the functionality of "wildcards" which are characters that can be substituted for all possible characters, within a defined subset. Other search engines will not have this function (see below). When there are options to search in a particular location (i.e. where in a document to search), the preference will always be the title, keywords and abstract (in Web of Science this would be the 'topic' search section, in others this may be the 'subject' search section), where there is no option to choose, the default will be accepted. Where complex search strings are permissible, search terms will be based on the following phrases (where * denotes a wild card to search for alternate endings or beginnings and $\$$ denotes a substitution or nothing): "fauna* OR "benth" OR scaveng* OR by\$catch $O R$ maerl OR coral* OR biota OR biogenic OR (hard AND bod") OR (soft AND bod") OR "flora" OR "invertebrate* $A N D$

"trawl" OR ((bottom OR mobile OR towed OR commercial OR benthic OR demersal) AND fishing) OR harvest* OR *dredg* OR digging OR (bait AND collect*) OR "raking OR scallop drag" OR dragging

AND

experiment* OR comparative OR BACI OR ((differ* OR known OR gradient $O R$ range $O R$ vari* $O R$ change $O R$ contrasting OR distinct) AND (fishing OR trawling OR dredging OR dragging OR disturbance) AND (pressure OR level OR amount OR frequencies OR intensities OR histories)) OR ((trawled OR fished OR disturbed OR harvest* OR heavily OR within OR impact OR inside OR after OR following OR treatment OR trial) AND (un \$trawled OR non\$fished OR un\$fished OR un\$disturbed OR un\$harvested OR non\$harvested OR lightly OR outside OR before OR prior OR adjacent OR control OR reference OR protected OR MPA OR closed))

Where it is not possible to search using the complex string above, the simple phrase below will be used in a structure appropriate for the particular website/database in question:

("trawl OR *dredge*) AND (effect* OR impact*)

The input may have to be done by hand where wildcards and Boolean operators are not allowed. Whilst the latter examples are not as explicit as the primary search query, there is a need for a pragmatic approach considering the high number of specialist search engines being targeted by the review.

\section{Databases}

Databases and websites often bias the results they show because algorithms include aspects of past search queries and website tracking cookies. Therefore search results can differ among individuals and geographic regions. There are search engines that provide neutral searches. However, these would not capture the full range of literature sources sought in the systematic review. To avoid bias in search 
results while attempting to capture all sources of published and grey literature, all browsing history and cookies will be disabled before every individual search (for example using google.com you have to "disable customizations based on web history"), and no accounts will accessed during the search (for example logging into a g-mail account may bias search hits based on profile preferences). For repeatability purposes a record of the search history will be maintained and all searching will be done from a university desktop computer in the School of Ocean Sciences at Bangor University, Wales, UK. Further search information and logistics are available upon request.

The following computerised databases will be searched and all the hits will be taken into consideration for inclusion/exclusion:

1) Aquatic Sciences and Fisheries Abstracts (ASFA) www.lib.noaa.gov/researchtools/journals/databases. html

2) BioOne Abstracts and Indexes - www.lib.noaa.gov/ researchtools/journals/databases.html

3) Conference papers index - www.lib.noaa.gov/ researchtools/journals/databases.html

4) Copac - www.copac.ac.uk

5) Digital Dissertations Online - www.lib.umn.edu/ indexes/digitaldissertations

6) Directory of open access journals - www.lib.noaa. gov/researchtools/journals/databases.html

7) E-Print network - www.lib.noaa.gov/researchtools/ journals/databases.html

8) Greenfile - www.lib.noaa.gov/researchtools/journals/ databases.html

9) Index to Theses Online - www.theses.com

10) ISI Web of Science - http://wokinfo.com/

10) JSTOR: the scholarly journal archive - www.lib.noaa. gov/researchtools/journals/databases.html

12) National Academies Press (NAP) - www.lib.noaa. gov/researchtools/journals/databases.html

13) National Research Council Canada - www.lib.noaa. gov/researchtools/journals/databases.html

14) Natural Environment Research Council - www.nerc. ac.uk

- NB. Includes: British Geological Survey (BGS); National Oceanography Centre (NOC); Centre for Ecology and Hydrology (CEH); National Centre for Atmospheric Science (NCAS)

15) National Oceanic and Atmospheric eBook collection - www.lib.noaa.gov/researchtools/journals/databases. html

16) National Oceanic and Atmospheric Library and information network catalog - www.lib.noaa/gov

17) Oceanic Abstracts - www.lib.noaa.gov/researchtools/ journals/databases.html
18) PubMed - www.lib.noaa.gov/researchtools/journals/ databases.html

19) Science Accelerator - www.lib.noaa.gov/researchtools/journals/databases.html

20) Science Direct - www.sciencedirect.com/

21) Science.gov - www.lib.noaa.gov/researchtools/journals/ databases.html

22) Scopus - www.scopus.com

23) Worldcat.org - www.lib.noaa.gov/researchtools/ journals/databases.html

\section{Websites}

Where the search engine uses a probabilistic algorithm for displaying search hits (which means that items are ranked in priority order of similarity), the first 50 hits will be taken into consideration for inclusion/exclusion. When this is not the case and other bibliometric methods are employed such as popularity impact or date, the first 100 hits will be taken into consideration for inclusion/exclusion. The following computerised websites will be searched

24) Google - www.google.com

25) Google Scholar - www.scholar.google.com

26) Scirus - http://www.scirus.com (all journal sources)

\section{Specialist sources}

Websites of relevant specialist organisations, listed below, will also be searched. Bibliographies of included material will be searched for relevant references. Link pages of websites will be followed to look for relevant organisations that may have been missed by these searches. Authors of relevant articles will also be contacted for further recommendations, and for provision of any unpublished material or missing data.

27) Alaska Seafood Cooperative - www. alaskaseafoodcooperative.org

28) British Ecological Society - www.britishecologicalsociety.org

29) Centre for Ecology and Hydrology - www.ceh.ac.uk

30) Centre for Environment, Fisheries and Aquaculture Science www.cefas.defra.gov.uk

31) Commonwealth Scientific and Industrial Research Organisation - www.csiro.au

32) Department for the Environment, Food and Rural Affairs - www.defra.gov.uk

33) Department of Fisheries and Oceans Canada - www. dfo-mpo.gc.ca/index-eng.htm

34) Food and Agriculture Organization of the United Nations - www.fao.org

35) Fisheries Research Service - www.scotland.gov.uk

36) French Research Institute for Exploitation of the Sea - wwz.ifremer.fr/institut_eng 
37) Institute of Marine Engineering, Science and Technology - www.imarest.org

38) International Council for the Exploration of the Sea - www.ICES.dk

39) Joint Nature Conservation Committee - www.jncc. defra.gov.uk

40) Marine Conservation Alliance - www. marineconservationalliance.org

41) Marine Stewardship Council - www.msc.org

42) National Oceanic Atmospheric Administration - www. noaa.gov

43) Natural England - www.naturalengland.org.uk

44) Natural Resources Wales - www.naturalresourceswales.gov.uk

45) National Institute of Water and Atmospheric Research - www.niwa.co.nz

46) Northern Ireland Environment Agency - www. doeni.gov.uk

47) National Oceanic and Atmospheric Administration (NOAA) Regional Fisheries websites: Alaska, Northeast, Pacific Islands, Southeast and Caribbean and West Coast - www.nmfs.noaa.gov/index.html

48) North Pacific Marine Science Organization - www. pices.int

49) Northwest Atlantic Fisheries Organization - www. nafo.int

50) Scottish Natural Heritage - www.snh.gov.uk

51) The Nature Conservancy - www.nature.org

52) World Wide Fund for Nature - www.wwf.org.uk

The first 50 hits (Word and/or PDF documents) from each search will be checked for relevant pages or documents containing data. All references retrieved from the computerised databases will be exported into a bibliographic software package (Endnote) prior to assessment of relevance using inclusion criteria.

\section{Bibliographies}

Bibliographies of all articles accepted for full text viewing will be hand searched to identify any additional evidence. Web based bibliographies identified during the web searching phase will also be checked for additional references. Subject experts and practitioners will be contacted for additional references and authors of included studies may be requested to provide any unpublished material or missing data that may be relevant to the review. Special symposia concerning the effects of bottom fishing on benthic biota will be examined as well as current bibliographies on the effects of trawling on benthic biota known to the authors.

\section{Study collection}

Figure 1 summarises the process of searching and screening articles for relevance. Articles identified by the searches will be examined and will be selected initially based upon title and abstract relevance and subsequently on methodological integrity. An Endnote database will be used to organise all the articles, and to ensure duplicates are removed. The selection criteria for relevant articles will attempt to systematically remove articles that do not provide relevant data. The development of the inclusion/exclusion criteria is an iterative process, the outcome of which influences the conclusions of the review, and therefore must be objective [33,34]. When an article is border-line, or when there is insufficient information to exclude an article, it will be included for consideration in the next round. All articles will be recorded with justification for inclusion/exclusion.

To estimate the effects of between-reviewer variance in assessing relevance, two reviewers will apply the inclusion criteria to a sample of $10 \%$ of articles, or 250 articles, (whichever is greater) at the start of the abstract filtering stage. The kappa statistic [35] will be calculated, which measures the level of agreement between reviewers. The kappa statistic must be at or above 0.6 $(\geq 0.6,[34,36])$, if it falls below this level the same reviewers will discuss the discrepancies and clarify the interpretation of the inclusion criteria. This may entail a modification of the criteria specification. After this discussion, one reviewer will apply the inclusion criteria to the rest of the citations.

\section{Study inclusion/exclusion criteria}

There are three steps to the inclusion/exclusion process, at each step the key requirements will become more specific as more information becomes available. At the primary stage, the following criteria must be met for an article to pass to the next stage:

- Relevant subjects(s): Marine benthic biota (flora and fauna)

- Types of exposure: Experimental or comparative bottom fishing activities

- Types of comparator: No exposure or less exposure to bottom fishing gear

- Types of outcome: Measurable effect (i.e. change and no change are both effects, so non-significant results will be included) in a component of benthic biota (species, taxon, trophic group etc.)

- Types of Study: Before/after, control/impact study, or estimates of the response of benthic biota metrics from two or more areas of the seabed subjected to different intensities of fishing disturbance

When there is insufficient information to exclude an article (for example the title contains limited information), the article will pass to the next stage of the process. The exclusion criteria at this stage are slightly 


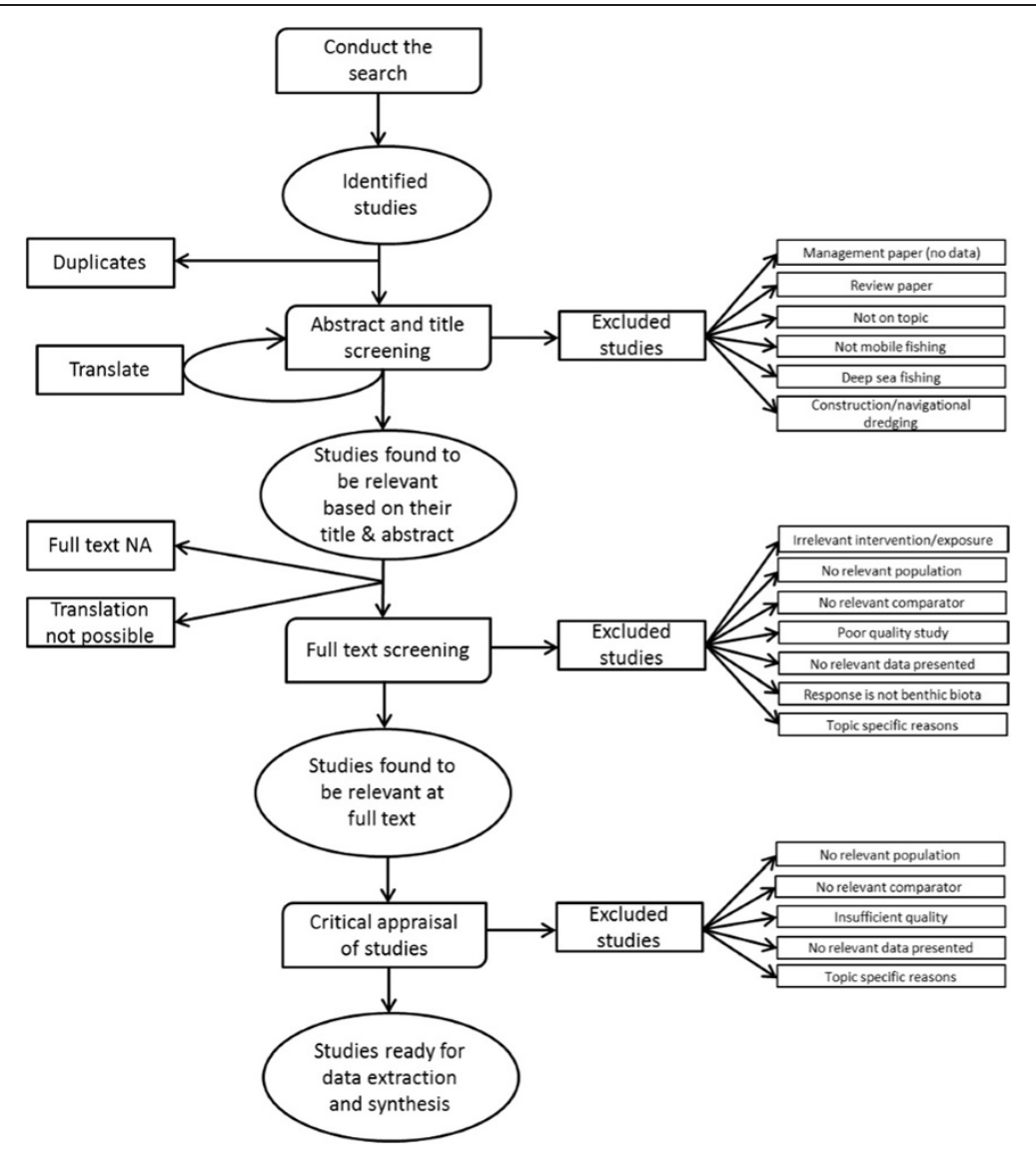

Figure 1 Flow diagram showing the development of the final bibliography to be used in the meta-analysis. NA= not available.

more straightforward. If there is no measure of the effect of bottom fishing on biological units of benthic flora or fauna, the study will not be included, but nonsignificant effects will be included. The exclusion criterion specifies that studies of the effects of deep sea or pelagic fishing will be excluded, as the focus of this review is the shelf areas. For those studies retained for inclusion based on their titles, the abstracts will be read. If there is no abstract, the article will immediately pass to the full text stage. If the study meets the inclusion criteria and does not contain any of the exclusion criteria at this point, the study will pass through to be read at the full text level. Exclusion criteria for the full text level of analysis will include studies for which: the predictor or response is not quantifiable, the bottom fishing intensity is not quantitative (except for comparative studies where estimates of relative intensity may be acceptable), the sample size is too small (i.e. if only 1 sample (e.g. Day grab/box core/trawl haul) is taken from areas with different intensities of bottom fishing), the methodologies are not robust enough or autocorrelation is an issue and no data have been presented in the results. The full exclusion criteria will likely develop throughout the systematic review process and details will be updated in the final systematic review paper and supporting materials.

\section{Study quality assessment}

Assessment of quality among the studies selected for this systematic review can be subjective. Variations in interpretation are therefore quantified as the 'risk of bias' in the estimates of change in state (abundance, diversity etc. which will be calculated as the effect size, or Hedges d') as a result of bottom fishing. High quality studies are defined as "statistically powerful and ecologically sound in their methods of data collection, analysis and interpretation" and are therefore are less at risk from bias than their lower quality counterparts.

At the meta-analysis stage each study will have an effect size that describes the magnitude and direction of the outcome using the Hedges' d statistic. Hedges' d is a standardised mean difference (thus suitable for combining studies using different scales) between treatment and control groups. Hedges' d reflects the difference between the distributions in two groups [35], and describes a 
comparison of estimates of means where $\bar{Y}_{1}$ and $\bar{Y}_{2}$ are means, with respective sample sizes $n_{1}$ and $n_{2}$ and standard deviations $S_{1}$ and $S_{2}$ :

$$
\mathrm{d}=\frac{\bar{Y}_{1-\bar{Y}_{2}}}{\sqrt{\frac{\left(n_{1}-1\right) S_{1}^{2}+\left(n_{2}-1\right) S_{2}^{2}}{n_{1}+n_{2}-2}}} \cdot \mathrm{J}
$$

$J$ is a correction for small sample size meaning it works well with as few as five studies, J is given by:

$$
J=1-\frac{3}{4\left(n_{1}+n_{1}-2\right)-1}
$$

The variance for Hedges' d is:

$$
V_{d}=\frac{n_{1}+n_{2}}{n_{1} n_{2}}+\frac{d^{2}}{2\left(n_{1}+n_{2}\right)}
$$

\section{Potential effect modifiers and reasons for heterogeneity}

- Unknown in situ variation in natural disturbance may have a positive or negative bias on the effect size

- Different gear types vary in their intensity and mechanism of impact on the marine benthos

- The historical footprint of bottom fishing effort is likely to be spatially heterogeneous and in some areas unquantified

- Spatial heterogeneity in data abundance and quality is expected, giving higher precision estimates of bottom fishing effects in some areas and lower precision in others

- Pseudo replication is often present in trawl impact studies, decreasing the precision of the result and increasing unknown bias

- Sample size (and therefore the precision of the effect size) is expected to vary between studies

- Publication bias will exist, where there is a tendency for significant rather than non-significant results to be published. Therefore a positive bias (greater impact) may be present in the results

- Studies may sample sites that are not representative of areas impacted by fishing. Here the bias may increase or decrease the impact of fishing for the areas

- Natural benthic productivity and recoverability potential may depend on environmental factors such as oceanographic features (e.g. fronts), pipelines, wrecks, natural reefs and mounds, nutrient cycling and natural disturbance. If these factors have an effect and it is not quantified, a positive or negative bias may exist

- Direct and diffuse effects of long-term trawling disturbance may result in large-scale alterations in benthic habitats. Consequently, the state of control sites will not provide an adequate baseline and comparisons with the controls will introduce a negative bias (imply lower impact)

\section{Data extraction strategy}

Studies accepted at full text will be classified into either experimental or comparative. In both cases, data will be recorded in a database, building on a database developed previously [3]. All articles excluded from the review will be recorded in a spreadsheet with justification for their removal. The spreadsheet will be made publically available. See (Additional file 3) for more details.

Descriptor data that will be extracted include:

- Study Type (comparative or experimental)

- Treatment (gear used or activity e.g. bait digging/ electric pulse)

- Disturbance description (including the number of discrete disturbance treatments (in time), the intensity of each disturbance treatment (at each time), the area of the disturbance $\left(\mathrm{m}^{2}\right)$ including the minimum and maximum scales of disturbance events)

- Sampling gear used to quantify the impact (e.g. video survey or day grab)

- Geographic location of the study (latitude and longitude)

- Physical and biological information including fauna analysed and abiotic variables recorded (e.g. depth, sediment type)

- Data quality - includes the number of replicate sites or replicate plots including the area or volume of sediment sampled, and the number of samples collected within each replicate area.

Study data that will be extracted include:

- Response type - the response type (fauna, physical etc.)

- Taxonomy - Phylum, class, order

- Response metric - the type of raw data, abundance, count, biomass etc.

- Time interval between treatment and sampling (measured in whole days)

- Units of change - raw units as reported on in the study as well as standardized units to $\mathrm{m}^{2}$ per specified disturbance level

- Background disturbance levels (ideally quantified by annual trawl events if known, otherwise categorised to high medium and low if possible) of treatment and control sites

- Control data - including the results (and variance thereof) from the study, the number of samples taken and volume of material sampled 
- Treatment data - the results from study and variance, number of samples taken from each site/ plot and volume of material sampled

- Measures of the means and standard deviations (or variance) of the experimental or comparative studies.

\section{Data synthesis}

Previous reviews $[3,13]$ have demonstrated that sufficient data are available for meta-analysis, but that investigations of heterogeneity (reasons for differences in the effects of fishing e.g. habitat/gear/natural disturbance) are limited by data availability. Our synthesis will therefore consist of meta-analytical methods to address the primary question with meta-regression and subgroup analyses used to investigate reasons for heterogeneity between studies (see [37] for more details on methodologies), or possibly using a mixed model with 'study' as a random effect.

Studies will first be classified by variables that affect the degree of bottom fishing impact (see section 3.3 "descriptor data"). Response for specific taxa will be treated as independent observations so as to investigate the effects of the potential explanatory variables on the response of the population, regardless of taxa [3]. The response will be measured by using Hedges d' as the effect size statistic.

\section{Additional files}

Additional file 1: Defining the Research Question. This additional file defines the research question using the stakeholder consultation exercise that prioritises the most pertinent issues pertaining to the use and effects of mobile fishing gears.

Additional file 2: Scoping the search. This additional file describes the process of scoping the search using the PICO structure. The search map is presented that leads to the definition of the final search string used. The hits from this search string (obtained from Web of Science) are then used to assess the relevance of the search string to the hits we would expect to obtain.

Additional file 3: Data Extraction. This file shows the criteria to be extracted during the data extraction stage of the systematic review process.

\section{Competing interests}

Authors' affiliations are listed on the title page of this review. The study is funded by the following:

Packard Foundation

Walton Foundation

American Seafoods Group U.S.

Blumar Seafoods Denmark

Espersen Group

Glacier Fish Company LLC U.S.

Independent Fisheries Limited N.Z.

Nippon Suisan (USA), Inc.

Pacific Andes International Holdings, Ltd.

San Arawa, S.A.

Sanford Ltd. N.Z.

Sealord Group Ltd. N.Z.

South African Trawling Association

\section{Authors' contributions}

MJK, SJ and $\mathrm{RH}$ conceived the idea of the systematic review in this subject, $\mathrm{KMH}$ drafted the manuscript, AR, ASP, JC, JGH, KMH, MJK, RAM, RH, ROA, RP,
SJ, all submitted feedback on the protocol manuscript prior to submission. All authors read and approved the final manuscript.

\section{Acknowledgements}

We would like to acknowledge all stakeholders working in affiliation with the Study Trawl Committee for their feedback and input to this document, as well as those giving feedback via the CEBC website. We would also like to thank all the institutions funding salaries of study committee members.

\section{Author details}

${ }^{1}$ School of Ocean Sciences, Menai Bridge, Bangor University, Wales LL59 5AB, UK. ${ }^{2}$ Centre for Environment, Fisheries and Aquaculture Science, Lowestoft NR33 OHT, UK. ${ }^{3}$ RACE Division, Alaska Fisheries Science Center, National Marine Fisheries Service, National Oceanic and Atmospheric Administration, 7600 Sand Point Way N.E, Seattle, WA 98115, USA. ${ }^{4}$ CSIRO Oceans and Atmosphere Flagship, EcoSciences Precinct 41 Boggo Road, DUTTON PARK, Qld. 4102, GPO Box 2583, Brisbane, QLD 4001, Australia. ${ }^{5}$ School of Aquatic and Fishery Sciences, University of Washington, Box 355020, Seattle, WA 98195, USA. 'Graduate School of Oceanography, University of Rhode Island, 215 South Ferry Road, Narragansett, Rhode Island, USA. ${ }^{7}$ Centro Nacional Patagónico, Blvd. Brown 2915, U 9120 ACF, Puerto Madryn, Chubut, Argentina. ${ }^{8}$ IMARES, Institute for Marine Resources and Ecosystem Studies, Haringkade, 11976 CP IJmuiden, Netherlands.

Received: 17 March 2014 Accepted: 15 August 2014

Published: 25 November 2014

\section{References}

1. Grieve C, Brady DC, Polet H: Best Practices for Managing, Measuring, and Mitigating the Benthic Impacts of Fishing, Final report to the Marine Stewardship Council; 2011

2. Thrush SF, Hewitt JE, Cummings VJ, Dayton PK, Cryer M, Turner SJ, Funnell GA, Budd RG, Mulburn CJ, Wilkinson MR: Disturbance of the marine benthic habitat by commercial fishing: Impacts at the scale of the fishery. Ecol App/ 1998, 83(3):866-879.

3. Kaiser MJ, Clarke KR, Hinz H, Austen MCV, Somerfield PJ, Karakassis I: Global analysis and prediction of the response of benthic biota and habitats to fishing. Mar Ecol-Prog Ser 2006, 311:1-14.

4. Prena J, Schwinghammer P, Rowell T, Gordon DC, Gilkinson KD, Vass WP McKeown DL: Experimental otter trawling on a sandy bottom ecosystem of the Grand Banks of Newfoundland: analysis of trawl bycatch and effects on epifauna. Mar Ecol-Prog Ser 1999, 181:107-124.

5. Smith CJ, Papadopoulou KN, Dilberto S: Impact of otter trawling on an eastern Mediterranean commercial trawl fishing ground. ICES J Mar Sci 2000, 57:1340-1351.

6. Watling L, Findlay RH, Mayer LM, Schick DF: Impact of scallop drag on the sediment chemistry, microbiota and faunal assemblages of a shallow subtidal marine benthic community. I Sea Res 2001, 46:309-324.

7. Jones JB: Environmental impact of trawling on the seabed: A review. New Zeal J Mar Fresh 1992, 26(1):59-67.

8. Dayton PK, Thrush SF, Agardy MT, Hofman RJ: Environmental effects of marine fishing. Aquat Conserv 1995, 5:205-232.

9. Jennings $S$, Kaiser MJ: The effects of fishing on marine ecosystems. Adv Mar Biol 1998, 34:201-352.

10. Kaiser MJ, Edwards DB, Armstrong PJ, Radford K, Lough NEL, Flatt RP, Jones $\mathrm{HD}$ : Changes in megafaunal benthic communities in different habitats after trawling disturbance. ICES J Mar Sci 1998, 55:353-361.

11. Auster PJ, Langton RW: The effects of fishing on fish habitat. In Fish Habitat: Essential Fish Habitat and Restoration, Symposium 22. Am Fish S S. Edited by Benaka L; 1999:150-187.

12. National Research Council: Effects of Trawling and Dredging on Seafloor Habitat, Committee on Ecosystem Effects of Fishing: Phase 1-Effects of Bottom Trawling on Seafloor Habitats, Ocean Studies Board, Division on Earth and Life Sciences, National Research Council. Washington, D.C: National Academy Press; 2002.

13. Collie JS, Hall SJ, Kaiser MJ, Poiner I: A quantitative analysis of fishing impacts on shelf-sea benthos. J Anim Ecol 2000, 69:785-798.

14. Anon: Report on the Study Group on the Effects of Bottom Trawling; 1998. ICES C.M. 1988/B:56. 30.

15. ICES: Report of the ICES Working Group on Fishing Technology and Fish Behaviour. Canada: St. John's, NF; 1999. ICES CM 1999/B: 1. 
16. ICES: Report of the ICES Working Group on Fishing Technology and Fish Behaviour. Haarlem, the Netherlands: ICES; 2000. 2000, ICES CM 2000/B: 03.

17. ICES: Report of the ICES Working Group on Ecosystem Effects on Fishing Activities. ICES; 2000. ICES CM 2000/ACME: 02.

18. ICES: Report of the ICES/FAO Working Group on Fishing Technology and Fish Behaviour. Gdynia, Poland. 2004. 2004, ICES CM 2004/B: 03.

19. FAO: Impact of Trawling and Scallop Dredging on Benthic Habitats and Communities, FAO Fisheries Technical Paper; 2005:472. ISBN 0429-9345.

20. Sanchez $P$, Demestre $M$, Ramon $M$, Kaiser MJ: The impact of otter trawling on mud communities in the northwestern Mediterranean. ICES J Mar Sci 2000, 57:1352-1358.

21. Turner MG, Romme WH, Gardner RH, O'Neill RV, Kratz TK: A revised concept of landscape equilibrium: disturbance and stability on scaled landscapes. Landscape Ecol 1993, 8:213-227.

22. Kaiser MJ, Ramsay K, Richardson CA, Spence FE, Brand AR: Chronic fishing disturbance has changed shelf sea benthic community structure. J Anim Ecol 2000, 69:494-503.

23. Jennings S, Dinmore TA, Duplisea DE, Warr KL, Lancaster JE: Trawling disturbance can modify benthic production processes. J Anim Ecol 2001, 70:459-475.

24. Thrush SF, Dayton PK: Disturbance to marine benthic habitats by trawling and dredging: Implications for marine biodiversity. Annu Rev of Ecol Syst 2002, 33:449-473.

25. Kaiser MJ, Spencer BE: Fish scavenging behaviour in recently trawled areas. Mar Ecol-Prog Ser 1999, 112:41-49.

26. Tuck ID, Hall SJ, Robertson MR, Armstrong E, Basford DJ: Effects of physical trawling disturbance in a previously unfished sheltered Scottish sea loch. Mar Ecol-Prog Ser 1998, 162:227-242.

27. Hanson M, Lindegarth M, Valentinsson D, Ulmestrand M: Effects of shrimptrawling on abundance of benthic macrofauna in Gullmarsfjorden, Sweden. Mar Ecol-Prog Ser 2000, 198:191-201.

28. Lindegarth $M$, Valentinsson $D$, Hansson M, Ulmestrand M: Effects of trawling disturbances on temporal and spatial structure of benthic soft-sediment assemblages in Gullmarsfjorden, Sweden. ICES J Mar Sci 2000, 57:1369-1376.

29. Rjinsdorp AD, Buys AM, Storbeck F, Visser EG: Micro-scale distribution of beam trawl effort in the southern North Sea between 1993 and 1996 in relation to the trawling frequency of the sea bed and the impact on benthic organisms. ICES J Mar Sci 1998, 55:403-419.

30. FAO: Options to Mitigate Bottom Habitat Impact of Dragged Gears, FAO Fisheries Technical Paper 506. ; 2007. ISBN ISBN 978-92-5-105876.

31. Collaboration for Environmental Evidence (CEE): Guidelines for Systematic Review and Evidence Synthesis in Environmental Management. ; 2013. Version 4.2. Environmental Evidence: [http://environmentalevidence.org/ Documents/Guidelines/Guidelines4.2.pdf]

32. Hilborn R, Jennings S, Kaiser M, Collie J, Parma A, McConnaughey R, Pitcher R, Hiddink J, Rijnsdorp A, Suuronen P, van Kooten T, van Denderen D, Hughes K, Amoroso R: Report of the Second Meeting of the Study Committee: Trawling: Finding Common Ground on the Scientific Knowledge Regarding Best Practices; 2013. Held 24-26 November 2013 IJmuiden Netherlands. http:/trawlingpractices.files.wordpress.com/2014/01/trawl-second-meeting-report.pdf.

33. Woodcock P, Pullin AS, Kaiser MJ: A standardised methodology for evaluating research syntheses in environmental science. Biol Conserv In press.

34. Pullin A, Stewart G: Guidelines for systematic review in conservation and environmental management. Cons Biol 2006, 20:1647-1656.

35. Borenstein M, Hedges L, Higgins JPT, Rothstein HR: Introduction to Meta-Analysis. Chichester, West Sussex, UK: John Wiley \& Sons Ltd; 2009

36. Centre for Evidence-Based Conservation (CEBC): Guidelines for Systematic Review and Conservation and Environmental Management, Version 4.0. Centre for Evidence-Based Conservation. Bangor, UK: Bangor University; 2010.

37. Koricheva J, Gurevitch J, Mengersen K: Handbook of Meta-analysis in Ecology and Evolution. Princeton University Press: 41 William Street, Princeton, New Jersey 08540; 2013

doi:10.1186/2047-2382-3-23

Cite this article as: Hughes et al:: Investigating the effects of mobile bottom fishing on benthic biota: a systematic review protocol. Environmental Evidence 2014 3:23.

\section{Submit your next manuscript to BioMed Central and take full advantage of:}

- Convenient online submission

- Thorough peer review

- No space constraints or color figure charges

- Immediate publication on acceptance

- Inclusion in PubMed, CAS, Scopus and Google Scholar

- Research which is freely available for redistribution

Submit your manuscript at www.biomedcentral.com/submit
Biomed Central 